\title{
Effect of Centrifuge Speed on Gel Extraction from Aloe Vera Leaves
}

\section{Chandegara VK ${ }^{1 *}$ and Varshney AK $^{2}$}

${ }^{1}$ Polytechnic in Agro-Processing, College of Agriculture, Engineering \& Technology, Junagadh, Agricultural University, Junagadh-362001 India

${ }^{2}$ Department of Processing and Food Engineering, College of Agricultural Engineering and Technology, Junagadh Agricultural University, Junagadh-362001 India

\begin{abstract}
This paper describes the extraction of gel from aloe vera leaves by use of method of centrifugation. The effect of different centrifuge speed, i. e. 2000,5000 and $10,000 \mathrm{rpm}$ at different temperature i.e. $5^{\circ} \mathrm{C}, 10^{\circ} \mathrm{C}$ and $32^{\circ} \mathrm{C}$ (ambient) ) and centrifuge holding duration i.e. 10, 20 and $30 \mathrm{~min}$, on gel recovery and quality parameters like, viscosity of gel, refractive index of gel, was studied. An effort has been made to optimize the centrifuge speed for gel extraction from aloe vera leaves. It was concluded that the extraction of gel from aloe vera should be carried at $10000 \mathrm{rpm}$ speed, $5^{\circ} \mathrm{C}$ temperature and 30 min duration, which yielded higher gel recovery and better quality of gel. Higher centrifuge speed leads more separation of gel molecules and fibers from aloe vera pulp to get clear gel.
\end{abstract}

Keywords: Aloe vera; Gel extraction; Centrifugation

\section{Introduction}

Aloe vera is a succulent that belongs to the liliaceae family. Aloe vera gel is the commercial name given to the fiber free mucilaginous exudate extracted from the hydroparenchyma of the succulent leaves of aloe vera (Aloe barbadensis Miller). Aloe vera gel (a clear, jelly-like material) is derived from tissue that comprises the inner portion of the leaves. Aloe vera gel is used as preservative coating for preservation of fruits [1] and food drinks for health supplements. Aloe gel is used for base in many cosmetic formulations and also used as medicine. Aloe vera contains biological active compounds which temperature sensitive and hence demands great care in processing. Aloe vera gel molecules are surrounded by the chain of sugar molecules surrounded [2]. Centrifugal action on Aloe gel break the chain of sugar molecules surrounded by gel molecules and leads more gel recovery and fibreless gel. Centrifugal separation of aloe vera gel is found its application in most prevalent gel extraction methods like hand filleting and whole leaf processing, from aloe vera (Figure 1).

Waller [3] had carried out study to investigate chemical constituents of aloe vera leaf gel and determined free amino acids, free monosaccharides and total saccharides released upon hydrolysis, sterols, and triterpenoids of the leaves of Aloe barbadensis Miller by extracting gel with water-acetone (1:1) and then acetone at room temperature. Shafi N [4] developed a commercially viable process for preparing a stable and pharmacological active crystalline substance from the fresh whole leaf. A review on processing of aloe vera leaf gel, has revealed aloe vera as a highly potential functional and valuable ingredient that exhibits relatively impressive biological functions of great interest in cosmetic, pharmaceutical and food industries [5]. It

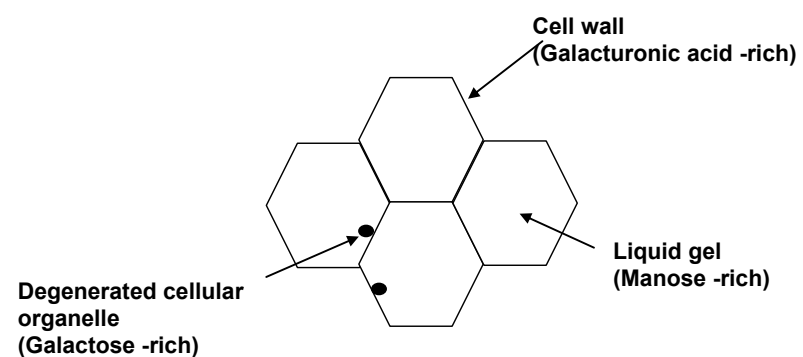

Figure 1: Aloe vera leaf pulp structure and its components $[4,11]$. also revealed the present processing technologies viz., gel stabilization technique, biological activity of aloe leaf gel and the effect of heat treatment on various constituents of gel.

Aloe vera processing industry demands pure gel for its cosmetic, nutritional and medicinal use. Reynolds and Dweck [6] reported a review update for aloe vera leaf gel and pointed out that scarce information is available for aloe vera processing particularly extraction of gel, though it has acquired great commercial importance for medicinal use and cosmetics products. Therefore, it is worthwhile to explore methods of centrifugal separation of aloe vera gel that can lead to an increase of gel recovery and less fiber content in gel. In aloe vera leaf, the gel molecules are surrounded by chain of sugar molecule. It is essential to break up this molecular chain and extract gel by application of centrifugal force. Under the centrifugal action, the speed of centrifuge play pivotal role in separation of gel from aloe vera pulp after removing the exudates. Yaron [7] have extracted gel from full sized mature leaves by centrifugation. After removal of the 'peel' the colorless hydroparenchyma was ground in a blender and centrifuged at $10,000 \mathrm{xg}$ for $30 \mathrm{~min}$ at $4^{\circ} \mathrm{C}$ to remove the fibers. Considering the above fact, it is necessary to standardize the centrifuge speed for optimum quality of gel for its cosmetic, medicinal and nutritional use.

\section{Materials and Methods}

\section{Materials}

The effect of centrifuge speed on extraction of gel from aloe vera and subsequent recovery and quality of extracted gel was studied. The matured aloe vera (Aloe barbadensis Miller) leaves were obtained from Department of Botany, College of Agriculture, Junagadh Agricultural University, Junagadh [8]. The freshly harvested aloe vera leaves were stored at 4 to $5^{\circ} \mathrm{C}$ prior to experimentation.

*Corresponding author: Chandegara VK, Polytechnic in Agro-Processing, Junagadh Agricultural University, Junagadh-362001 India, Tel: +91-9913109153; E mail: vkchandegara@jau.in

Received December 31, 2013; Accepted January 28, 2014; Published February 06, 2014

Citation: Chandegara VK, Varshney AK (2014) Effect of Centrifuge Speed on Gel Extraction from Aloe Vera Leaves. J Food Process Technol 5: 295. doi:10.4172/2157-7110.1000295

Copyright: (C) 2014 Chandegara VK, et al. This is an open-access article distributed under the terms of the Creative Commons Attribution License, which permits unrestricted use, distribution, and reproduction in any medium, provided the original author and source are credited. 


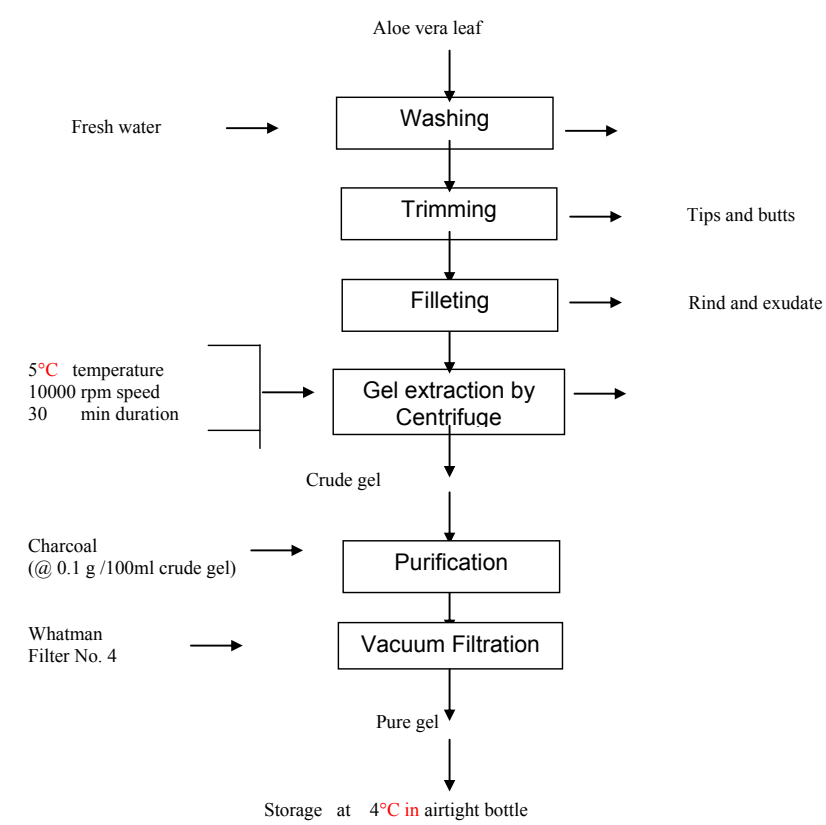

Figure 2: Process flow chart for aloe vera gel extraction $[1,8]$.

\section{Methodology}

The experiment was carried out by different unit operations like Aloe pulp grinding, Centrifugal separation and filtration of crude gel to obtain pure gel as shown in Figure 2.

Centrifugal separation of gel: The domestic blander (Boss make) was used to ground the fillets to obtain homogenized pulp. The $60 \mathrm{ml}$ pulp on volume basis in three samples were centrifuged in cold type centrifuge (Remi Instruments,Mumbai, India) for separation of gel and fiber [7]. The centrifuge temperature was set $5^{\circ} \mathrm{C}, 10^{\circ} \mathrm{C}$ and $32^{\circ} \mathrm{C}$ (ambient) with different centrifuge speed. Centrifuge test tubes of 100 $\mathrm{ml}$ capacity were hold for 10,20 and 30 min duration with different combination of treatments and $40 \%$ volume of test tubes was left to give sufficient space in for centrifugal action. The experiments were planned for 3 levels of (centrifuge speed of $\left(2000,5000\right.$ and $10,000 \mathrm{rpm}$ ), at $5^{\circ} \mathrm{C}$, $10^{\circ} \mathrm{C}$ and $32^{\circ} \mathrm{C}$ (ambient) centrifuge temperature for 10,20 and $30 \mathrm{~min}$ centrifuge duration.

Filtration unit: The filtration unit was consisted of vacuum pump, Buchner flask and Buchner funnel. The crude gel, which was obtained after centrifuge operation, was mixed with Charcoal for gel purification. The gel then was filtered in the filtration unit with the help of Whatman No. 4 filter paper for further analysis.

After giving different treatment of centrifuge speed, samples were brought for purification to remove impurities. The charcoal was mixed with crude gel for purification. The vacuum filtration method was used to obtain pure gel from crude gel.

The pure gel was collected in the test tubes for further analysis.

Fibre content: Crude gel is defined as the gel obtained after the centrifuge operation of Aloe vera pulp, while pure gel is the gel obtained after purification of the crude gel. The fibre content is defined as the difference between the dry weight of the crude gel and that of the filtered gel (pure gel). It was measured by filtering the homogenate through a $2.0 \mu \mathrm{m}$ muslin cloth followed by Whatman No. 4 filter paper under vacuum. Ten grams of the filtrate was placed in a dry glass petridish and dried at $105^{\circ} \mathrm{C} \pm 2{ }^{\circ} \mathrm{C}$ for 24 hours and its dry weight determined and the difference gives the fibre content [9].

Evaluation of gel quality parameters: Aloe gel quality was judged by its purity. Purity of gel was determined by the refractive index. The biological activity is the indication of more viscosity of gel. So higher viscosity of gel have more biological activity, which is important for its pharmaceutical and cosmetic use

\section{Viscosity}

The viscosity of a aloe vera gel is a very important property in the biochemical analysis as it is the indicator of active biological constituents. The Oswald viscometer was used for the measurement of viscosity of the aloe vera gel. After calibration the Oswald viscometer was filled to the lower calibration mark by applying suction with a rubber bulb and drawing the liquid analyte into the apparatus. The time required for the volume of liquid between the two marks to drain from the bulb is measured. The tube at the lower end of the upper bulb has a fixed length and radius, which was used along with the pressure differential column between the upper and lower ends of the apparatus to measure the viscosity.

The kinematic viscosity $(\mu)$ of liquid and the time (t) required to pass $50 \mathrm{cc}$ of liquid were correlated by the expression

$$
\begin{aligned}
& \mu=0.0026 \mathrm{t}-1.175 / \mathrm{t} \\
& \text { Where, } \\
& \mu=\text { Kinematic viscosity in Stokes } \\
& \mathrm{t}=\text { time in seconds to collect } 50 \mathrm{cc} \text { of gel. }
\end{aligned}
$$

\section{The unit of kinematic viscosity was then converted in $\mathrm{cm}^{2} \mathrm{~s}^{-1}$}

Refractive index: Refractive index is the physical property of gel determines the purity of gel as compared to double distilled water and not total soluble solid content of gel. Gel with lowest refractive index, is the best treatment for extraction process. More refractive index indicates the impurities in the extracted gel.

The Abbey Refractometer was used for measurement of refractive index having range of refractive Indices between 1.3000 and 1.7000 with an accuracy of +0.0002 . It was calibrated with known refractive indices i.e. doubled distilled water $(1.3323)$ at $27^{\circ} \mathrm{C} \pm 0.2^{\circ} \mathrm{C}$. Two drops of aloe vera gel were placed on the Refractometer prism surface and closed carefully. The mirror was adjusted until the reading was sharp. The instrument was allowed to stand for a few minutes before the reading was taken so that the sample and instrument came to equilibrium. The reading was taken when the blue and yellow shade crossed the cross mark.

\section{Design of experiments}

The experiments were planned using four factor completely randomized design. The treatments consisted of 2 levels of acetone, 3 levels of centrifuge temperature, 3 levels of centrifuge speed and 3 levels of centrifuge duration. Independent variables were acetone i.e. without addition of acetone, and $10 \%$ addition of acetone, centrifuge temperature i.e. 5,10 , and 32 (ambient) ${ }^{\circ} \mathrm{C}$, centrifuge speed i.e. 2000 , 5000 and 10,000 rpm and centrifuge duration i.e. 10, 20 and $30 \mathrm{~min}$. Dependent variables were gel recovery, $(\%)$ viscosity of gel, $\left(\mathrm{cm}^{2} \mathrm{~s}^{-1}\right)$ and refractive index of gel. Experiment was planned in Factorial Completely Randomized Design comprising of fifty four treatments with three replications. In all 54 experiments were conducted and results obtained were analyzed statistically. The analysis of variance along with the 


\begin{tabular}{|c|c|c|c|c|c|c|c|c|c|}
\hline \multicolumn{2}{|c|}{ Source of variation } & d.f. & S.S. & M.S.S. & Cal. F & Tab. F 1\% & S.E.M. \pm & C.D. @ 5\% & Test \\
\hline \multicolumn{2}{|c|}{ Three levels of Centrifuge speed } & 2 & 8745.568 & 4372.784 & 1790.122 & 3.12 & 0.213 & 0.597 & Sig. \\
\hline \multicolumn{2}{|c|}{$\begin{array}{l}\text { Three levels of Centrifuge speed with two levels of } \\
\text { acetone }\end{array}$} & 2 & 24.833 & 12.416 & 5.083 & 3.12 & 0.301 & 0.844 & Sig. \\
\hline \multicolumn{2}{|c|}{$\begin{array}{l}\text { Three levels of Centrifuge speed with three levels of } \\
\text { temperature }\end{array}$} & 4 & 41.679 & 10.420 & 4.266 & 2.43 & 0.368 & 1.034 & Sig. \\
\hline \multicolumn{2}{|c|}{$\begin{array}{l}\text { Three levels of Centrifuge speed with three levels of } \\
\text { centrifuge holding time }\end{array}$} & 4 & 130.906 & 32.727 & 13.398 & 2.43 & 0.368 & 1.034 & Sig. \\
\hline \multicolumn{2}{|c|}{$\begin{array}{l}\text { Three levels of Centrifuge speed, two levels of acetone } \\
\text { and three levels of temperature }\end{array}$} & 4 & 67.984 & 16.996 & 6.958 & 2.43 & 0.521 & 1.462 & Sig. \\
\hline \multicolumn{2}{|c|}{$\begin{array}{l}\text { Three levels of Centrifuge speed with three levels of } \\
\text { temperature and three levels of holding time }\end{array}$} & 8 & 49.757 & 6.220 & 2.546 & 2.01 & 0.638 & 1.790 & Sig. \\
\hline \multicolumn{2}{|c|}{$\begin{array}{l}\text { Three levels of different centrifuge speed with two levels } \\
\text { of acetone and three levels of holding time }\end{array}$} & 4 & 98.543 & 24.636 & 10.085 & 2.43 & 0.521 & 1.462 & Sig. \\
\hline \multicolumn{2}{|c|}{$\begin{array}{l}\text { Three levels of different centrifuge speed with two levels } \\
\text { of acetone, three levels of temperature and three levels } \\
\text { of holding time }\end{array}$} & 8 & 28.322 & 3.540 & 1.449 & 2.01 & 0.902 & 2.532 & NS \\
\hline \multicolumn{2}{|c|}{ Error } & 108 & 263.815 & 2.443 & & & & & \\
\hline \multicolumn{2}{|l|}{ Total } & 80 & & & & & & & \\
\hline \multicolumn{10}{|c|}{ C.V,$\%=2.68$} \\
\hline $\begin{array}{l}\text { d.f. } \\
\text { S.S. } \\
\text { M.S.S. } \\
\text { Cal. F } \\
\text { Tab. F 1\% } \\
\text { S.E.M. } \\
\text { C.D. } \\
\text { C.V. }\end{array}$ & $\begin{array}{l}=\text { degree of freedom } \\
=\text { sum of squares } \\
=\text { mean of sum of squares } \\
=\text { calculated F vale } \\
=\text { table F value } \\
=\text { standard error of mean } \\
=\text { critical difference } \\
=\text { coefficient of variation }\end{array}$ & & & & & & & & \\
\hline
\end{tabular}

Table 1: Analysis of variance table crude gel recovery.

level of significance was also determined. Subsequently, the principal components analysis was carried out to get the single optimum values of independent variables for the extraction gel from aloe vera leaves.

\section{Statistical Analysis}

The statistical analysis of experiment was carried out at Statistics Department, College of Agriculture, Junagadh Agricultural University, Junagadh, with Completely Randomized Design. The data of results were analyzed and interpreted by using Microsoft excel programme. The F-test was carried out to determine whether the effect was significant or not. Critical difference and Coefficient variation were considered for the interpretation of data.

\section{Results and Discussion}

\section{Effect of centrifuge speed on gel extraction process}

The centrifugation process was carried out to separate solid particles from pulp for getting crude gel. The aloe vera contains gel molecules surrounded by sugar molecules. Centrifugal force is required to break this chain of sugar molecules. It was seen from the results that, the gel recovery and viscosity increased with the increase of centrifuge speed, whereas refractive index decreased with the increase of centrifugal speed. The statistical analysis had shown that all the quality parameters were found to be significant at $5 \% \mathrm{Cd}$.

\section{Effect of centrifuge speed on gel recovery}

Results of analysis of variance for aloe vera gel recovery (\%) from pulp are summarized in Table 1 . It was clear from this analysis that variations among the various centrifuge speed and its interaction with acetone level, varying temperature for different holding time was found to be significant at $5 \% \mathrm{Cd}$. Therefore, the use of the complete randomized design in this experiment was essential to eliminate the variance among the various centrifuge speed with temperature and centrifuge durations as it was laboratory experiment. The results in the table also indicated that the effect of various centrifuge speed with temperature and centrifuge duration on gel recovery was statistically significant at $5 \% \mathrm{Cd}$. The gel recovery shows non-significant effect when all the independent variable was considered.

The results in Table 2 show that the mean values of aloe vera gel recovery at $10000 \mathrm{rpm}$ centrifuge speed were significantly higher than $2000 \mathrm{rpm}$ centrifuge speed as control. The average gel recovery of gel extraction at $10,000 \mathrm{rpm}$ samples were about $30 \%$ higher than those of the controls (The maximum gel recovery i.e. $71.33 \%$ from aloe vera leaf pulp, was found at $32^{\circ} \mathrm{C}$ temperature, $10000 \mathrm{rpm}$ speed and 30 min duration with $10 \%$ of acetone treatment and minimum recovery of $42.50 \%$ was found at $5^{\circ} \mathrm{C}$ temperatures, $2000 \mathrm{rpm}$ speed and 10 min duration for without acetone treatment). The higher gel recovery at higher speed i.e., 10,000 rpm may be attributed due the separation of solid particles from pulp and break down of the chain of sugar molecules. This was in accordance with findings by Yaron [7] who had extracted $300 \mathrm{ml}$ gel from leaves weighing 800 g i.e., $37.5 \%$ gel recovery from whole leaf and $75.0 \%$ gel recovery from pulp considering $50 \%$ aloe vera leaf pulp recovery at 10,000 x g centrifuge speed for $30 \mathrm{~min}$ at $4^{\circ} \mathrm{C}$. This phenomenon suggested that the higher centrifuge speed may have an effect in breaking the intercellular forces in aloe vera leaf gel tissues, which may lead to release of more of gel molecules.

It was observed that increase in centrifuge speed with different temperature, and varying holding time increased the gel recovery (Table 2). When centrifuge speed was increased from $2000 \mathrm{rpm}$ (42.50 - 56.50 $\%)$ to $5000 \mathrm{rpm}(45.72-64.78 \%)$, there was 7.0 to $15.0 \%$ increase in gel recovery observed. Increase in centrifuge speed from $5000 \mathrm{rpm}(45.72$ - $64.78 \%)$ to $10000 \mathrm{rpm}(63.89-71.33 \%)$ resulted about 12.0 to 40.0 $\%$ more gel recovery among various treatments. This may be attributed by the action of higher centrifugal force generated at high speed, which caused separation all the fibers and substance more efficiently and get more clear gel. 


\begin{tabular}{|c|c|c|c|c|c|c|}
\hline \multirow{4}{*}{ Experimental conditions } & \multicolumn{6}{|c|}{ Centrifuge duration (min) } \\
\hline & 10 & 20 & 30 & 10 & 20 & 30 \\
\hline & \multicolumn{3}{|c|}{ Without acetone } & \multicolumn{3}{|c|}{ With acetone (10 \%) } \\
\hline & \multicolumn{6}{|c|}{ Crude gel recovery (\%) } \\
\hline Centrifuge speed $2000 \mathrm{rpm}$ and $5^{\circ} \mathrm{C}$ temperature & 42.50 & 46.50 & 51.89 & 48.17 & 49.11 & 56.50 \\
\hline Centrifuge speed $2000 \mathrm{rpm}$ and $10^{\circ} \mathrm{C}$ temperature & 44.33 & 47.06 & 48.72 & 47.22 & 50.00 & 54.50 \\
\hline Centrifuge speed $2000 \mathrm{rpm}$ and $32^{\circ} \mathrm{C}$ temperature & 45.22 & 50.11 & 51.67 & 47.61 & 49.61 & 52.56 \\
\hline Centrifuge speed $5000 \mathrm{rpm}$ and $5^{\circ} \mathrm{C}$ temperature & 45.72 & 57.33 & 61.28 & 55.67 & 59.44 & 64.61 \\
\hline Centrifuge speed $5000 \mathrm{rpm}$ and $10^{\circ} \mathrm{C}$ temperature & 51.11 & 61.56 & 64.78 & 55.61 & 57.28 & 63.83 \\
\hline Centrifuge speed $5000 \mathrm{rpm}$ and $32^{\circ} \mathrm{C}$ temperature & 54.50 & 62.94 & 62.67 & 55.72 & 60.39 & 62.50 \\
\hline Centrifuge speed $10000 \mathrm{rpm}$ and $5^{\circ} \mathrm{C}$ temperature & 63.89 & 66.33 & 70.28 & 63.44 & 70.17 & 69.56 \\
\hline Centrifuge speed $10000 \mathrm{rpm}$ and $10^{\circ} \mathrm{C}$ temperature & 63.94 & 65.22 & 67.89 & 64.00 & 67.44 & 70.22 \\
\hline Centrifuge speed $10000 \mathrm{rpm}$ and $32^{\circ} \mathrm{C}$ temperature & 64.22 & 66.28 & 69.61 & 65.44 & 67.67 & 71.33 \\
\hline
\end{tabular}

Table 2: Effect of centrifuge speed with different proportion of acetone, varying temperature and duration on gel recovery (\%) from pulp.

\begin{tabular}{|c|c|c|c|c|c|c|c|c|c|}
\hline \multicolumn{2}{|r|}{ Source of variation } & d.f. & S.S. & M.S.S. & Cal. F & Tab. F 1\% & S.E.M. \pm & C.D. @ 5\% & Test \\
\hline \multicolumn{2}{|r|}{ Three levels of Centrifuge speed } & 2 & 0.202 & 0.101 & 71.590 & 3.12 & 0.005 & 0.014 & Sig. \\
\hline \multicolumn{2}{|r|}{ Three levels of Centrifuge speed with two levels of acetone } & 2 & 0.133 & 0.066 & 47.189 & 3.12 & 0.007 & 0.020 & Sig. \\
\hline \multicolumn{2}{|r|}{ Three levels of Centrifuge speed with three levels of temperature } & 4 & 0.062 & 0.016 & 11.013 & 2.43 & 0.009 & 0.025 & Sig. \\
\hline \multicolumn{2}{|r|}{ Three levels of Centrifuge speed with three levels of centrifuge holding time } & 4 & 0.006 & 0.002 & 1.131 & 2.43 & 0.009 & 0.025 & NS \\
\hline \multicolumn{2}{|c|}{$\begin{array}{l}\text { Three levels of Centrifuge speed, two levels of acetone and three levels of } \\
\text { temperature }\end{array}$} & 4 & 0.055 & 0.014 & 9.793 & 2.43 & 0.013 & 0.035 & Sig. \\
\hline \multicolumn{2}{|c|}{$\begin{array}{l}\text { Three levels of Centrifuge speed with three levels of temperature and three levels } \\
\text { of holding time }\end{array}$} & 8 & 0.069 & 0.009 & 6.167 & 2.01 & 0.015 & 0.043 & Sig. \\
\hline \multicolumn{2}{|c|}{$\begin{array}{c}\text { Three levels of different centrifuge speed with two levels of acetone and three } \\
\text { levels of holding time }\end{array}$} & 4 & 0.007 & 0.002 & 1.296 & 2.43 & 0.013 & 0.035 & NS \\
\hline \multicolumn{2}{|c|}{$\begin{array}{l}\text { Three levels of different centrifuge speed with two levels of acetone, three levels } \\
\text { of temperature and three levels of holding time }\end{array}$} & 8 & 0.048 & 0.006 & 4.237 & 2.01 & 0.022 & 0.061 & Sig. \\
\hline \multicolumn{2}{|r|}{ Error } & 108 & 0.152 & 0.001 & & & & & \\
\hline \multicolumn{2}{|r|}{ Total } & 80 & & & & & & & \\
\hline \multicolumn{10}{|c|}{ C.V., $\%=3.77$} \\
\hline \multicolumn{10}{|c|}{$\begin{array}{ll}\text { d.f. } & =\text { degree of freedom } \\
\text { S.S. } & =\text { sum of squares } \\
\text { M.S.S. } & =\text { mean of sum of squares } \\
\text { Cal. F } & =\text { calculated } \mathrm{F} \text { vale } \\
\text { Tab. F } 1 \% & =\text { table F value } \\
\text { S.E.M. } & =\text { standard error of mean } \\
\text { C.D. } & =\text { critical difference } \\
\text { C.V. } & \text { = coefficient of variation }\end{array}$} \\
\hline
\end{tabular}

Table 3: Analysis of variance table for viscosity.

From the results, it was evident that the higher centrifuge speed brought about increases in aloe vera gel recovery at $10000 \mathrm{rpm}$ speed samples extracted for the same amount of time and temperature than $2000 \mathrm{rpm}$ speed. In industrial practice, aloe vera gel should have more recovery at the same time clarity of gel i.e., purified gel. Therefore, it was desirable to extract the gel at higher centrifuge speed.

\section{Effect of centrifuge speed on Viscosity of gel}

In Table 3, the analysis of variance for viscosity of gel extracted by different centrifuge speed with acetone treatment, varying temperature and different holding duration of sample was presented and their results were given in Table 5. The statistical analysis had shown that the effect of centrifuge speed and its interaction with temperature, acetone and duration, on viscosity of gel was found to be significant. But for different centrifuge speed and its interaction with centrifuge duration was found to be non-significant. Similar trend was found for interaction with centrifuge duration and acetone. There was no uniform trend in viscosity for varying centrifuge speed and duration (Table 4). This had shown that viscosity of aloe vera gel was statistically not affected by centrifuge duration but only depends on temperature and centrifuge speed.

As summarized in Table 5, the maximum viscosity was recorded
$2.355 \mathrm{~cm}^{2} \mathrm{~s}^{-1}$ at $5^{\circ} \mathrm{C}$ temperature, $10000 \mathrm{rpm}$ centrifuge speed and $10 \mathrm{~min}$ duration for $10 \%$ addition of acetone treatment and minimum viscosity was found $0.521 \mathrm{~cm}^{2} \mathrm{~s}^{-1}$ at $32^{\circ} \mathrm{C}$ temperature, $2000 \mathrm{rpm}$ centrifuge speed and 10 min duration for without addition of acetone treatment. This showed that about $220 \%$ increases in viscosity of gel which mainly due to addition of $10 \%$ acetone. It was observed that increase in centrifuge temperature decreased the viscosity of gel and addition of acetone resulted increase in viscosity of gel. Therefore, it was clear from this study that viscosity of gel may be increased by an acetone pretreatment. The probable cause of this effect may be attributed to physical changes that occurred during acetone pretreatment. The acetone pretreatment makes formation of micro layer over gel molecules and causes the gel more viscous.

It was seen observed that increase in centrifuge speed with different temperature, and varying holding time increased the viscosity (Table 4). When centrifuge speed was increased from $2000 \mathrm{rpm}(0.521-2.098$ $\left.\mathrm{cm}^{2} \mathrm{~s}^{-1}\right)$ to $5000 \mathrm{rpm}\left(0.540-2.098 \mathrm{~cm}^{2} \mathrm{~s}^{-1}\right)$, there was no difference found in viscosity of gel and similar trend was observed while Increasing centrifuge speed from $5000 \mathrm{rpm}\left(0.540-2.098 \mathrm{~cm}^{2} \mathrm{~s}^{-1}\right)$ to $10000 \mathrm{rpm}$ $\left(0.545-2.355 \mathrm{~cm}^{2} \mathrm{~s}^{-1}\right)$ resulted marginal increase in viscosity of gel in various treatments. 


\begin{tabular}{|c|c|c|c|c|c|c|}
\hline \multirow{4}{*}{ Experimental conditions } & \multicolumn{6}{|c|}{ Centrifuge duration (min) } \\
\hline & 10 & 20 & 30 & 10 & 20 & 30 \\
\hline & \multicolumn{3}{|c|}{ Without acetone } & \multicolumn{3}{|c|}{ With acetone (10 \%) } \\
\hline & \multicolumn{6}{|c|}{ Viscosity of gel $\left(\mathrm{cm}^{2} \mathrm{~s}^{-1}\right)$} \\
\hline Centrifuge speed $2000 \mathrm{rpm}$ and $5^{\circ} \mathrm{C}$ temperature & 0.635 & 0.647 & 0.616 & 2.098 & 2.007 & 1.851 \\
\hline Centrifuge speed $2000 \mathrm{rpm}$ and $10^{\circ} \mathrm{C}$ temperature & 0.584 & 0.591 & 0.582 & 1.170 & 1.201 & 1.227 \\
\hline Centrifuge speed $2000 \mathrm{rpm}$ and $32^{\circ} \mathrm{C}$ temperature & 0.521 & 0.543 & 0.535 & 0.738 & 0.762 & 0.862 \\
\hline Centrifuge speed $5000 \mathrm{rpm}$ and $5^{\circ} \mathrm{C}$ temperature & 0.650 & 0.642 & 0.651 & 2.085 & 1.951 & 2.098 \\
\hline Centrifuge speed $5000 \mathrm{rpm}$ and $10^{\circ} \mathrm{C}$ temperature & 0.592 & 0.584 & 0.567 & 1.315 & 1.295 & 1.211 \\
\hline Centrifuge speed $5000 \mathrm{rpm}$ and $32{ }^{\circ} \mathrm{C}$ temperature & 0.543 & 0.538 & 0.540 & 0.859 & 0.846 & 0.837 \\
\hline Centrifuge speed $10000 \mathrm{rpm}$ and $5^{\circ} \mathrm{C}$ temperature & 0.635 & 0.659 & 0.675 & 2.355 & 2.194 & 2.192 \\
\hline Centrifuge speed $10000 \mathrm{rpm}$ and $10^{\circ} \mathrm{C}$ temperature & 0.595 & 0.584 & 0.596 & 1.304 & 1.276 & 1.252 \\
\hline Centrifuge speed $10000 \mathrm{rpm}$ and $32^{\circ} \mathrm{C}$ temperature & 0.545 & 0.548 & 0.563 & 0.921 & 0.904 & 0.923 \\
\hline
\end{tabular}

Table 4: Effect of centrifuge speed with different proportion of acetone, varying temperature and duration on viscosity of gel $\left(\mathrm{cm}^{2} \mathrm{~s}^{-1}\right)$.

\begin{tabular}{|c|c|c|c|c|c|c|c|c|c|}
\hline \multicolumn{2}{|r|}{ Source of variation } & d.f. & S.S. & M.S.S. & Cal. F & Tab. F 1\% & S.E.M \pm & C.D. @ 5\% & Test \\
\hline \multicolumn{2}{|r|}{ Three levels of Centrifuge speed } & 2 & $6.8 \times 10^{-5}$ & $3.4 \times 10^{-5}$ & 882.212 & 3.12 & $2.7 \times 10^{-5}$ & $7.5 \times 10^{-5}$ & Sig. \\
\hline \multicolumn{2}{|r|}{ Three levels of Centrifuge speed with two levels of acetone } & 2 & $1.3 \times 10^{-5}$ & $6.7 \times 10^{-6}$ & 173.610 & 3.12 & $3.8 \times 10^{-5}$ & $1.1 \times 10^{-4}$ & Sig. \\
\hline \multicolumn{2}{|c|}{ Three levels of Centrifuge speed with three levels of temperature } & 4 & $8.7 \times 10^{-7}$ & $2.2 \times 10^{-7}$ & 5.581 & 2.43 & $4.6 \times 10^{-5}$ & $1.3 \times 10^{-4}$ & Sig. \\
\hline \multicolumn{2}{|c|}{$\begin{array}{l}\text { Three levels of Centrifuge speed with three levels of centrifuge } \\
\text { holding time }\end{array}$} & 4 & $1.7 \times 10^{-6}$ & $4.4 \times 10^{-7}$ & 11.264 & 2.43 & $4.6 \times 10^{-5}$ & $1.3 \times 10^{-4}$ & Sig. \\
\hline \multicolumn{2}{|c|}{$\begin{array}{l}\text { Three levels of Centrifuge speed, two levels of acetone and three } \\
\text { levels of temperature }\end{array}$} & 4 & $1.7 \times 10^{-6}$ & $4.2 \times 10^{-7}$ & 10.903 & 2.43 & $6.5 \times 10^{-5}$ & $1.8 \times 10^{-4}$ & Sig. \\
\hline \multicolumn{2}{|c|}{$\begin{array}{c}\text { Three levels of Centrifuge speed with three levels of temperature } \\
\text { and three levels of holding time }\end{array}$} & 8 & $9.1 \times 10^{-7}$ & $1.1 \times 10^{-7}$ & 2.943 & 2.01 & $6.5 \times 10^{-5}$ & $2.3 \times 10^{-4}$ & Sig. \\
\hline \multicolumn{2}{|c|}{$\begin{array}{c}\text { Three levels of different centrifuge speed with two levels of acetone } \\
\text { and three levels of holding time }\end{array}$} & 4 & $5.5 \times 10^{-7}$ & $1.4 \times 10^{-7}$ & 3.568 & 2.43 & $6.5 \times 10^{-5}$ & $1.8 \times 10^{-4}$ & Sig. \\
\hline \multicolumn{2}{|c|}{$\begin{array}{l}\text { Three levels of different centrifuge speed with two levels of acetone, } \\
\text { three levels of temperature and three levels of holding time }\end{array}$} & 8 & $9.2 \times 10^{-7}$ & $1.1 \times 10^{-7}$ & 2.965 & 2.01 & $1.1 \times 10^{-4}$ & $3.2 \times 10^{-4}$ & Sig. \\
\hline \multicolumn{2}{|r|}{ Error } & 108 & $4.2 \times 10^{-6}$ & $4.0 \times 10^{-8}$ & & & & & \\
\hline \multicolumn{2}{|r|}{ Total } & 80 & & & & & & & \\
\hline \multicolumn{10}{|c|}{ C.V., $\%=0.015$} \\
\hline $\begin{array}{l}\text { d.f. } \\
\text { S.S. } \\
\text { M.S.S. } \\
\text { Cal. F } \\
\text { Tab. F 1\% } \\
\text { S.E.M. } \\
\text { C.D. } \\
\text { C.V. }\end{array}$ & $\begin{array}{l}=\text { degree of freedom } \\
=\text { sum of squares } \\
=\text { mean of sum of squares } \\
=\text { calculated } F \text { vale } \\
=\text { table } F \text { value } \\
=\text { standard error of mean } \\
=\text { critical difference } \\
=\text { coefficient of variation }\end{array}$ & & & & & & & & \\
\hline
\end{tabular}

Table 5: Analysis of variance table for refractive index.

In different centrifuge speed, there was decrease in viscosity of gel observed visually as the centrifuge duration increased from $10 \mathrm{~min}$ to $30 \mathrm{~min}$ and temperature raised from $5^{\circ} \mathrm{C}$ to $32^{\circ} \mathrm{C}$. This indicates that viscosity of gel is affected by temperature and holding time for extraction process. This may be due to existence of biological constituents get lost at higher temperature and longtime extraction process. It was said that, higher was the viscosity of aloe vera gel better would be the quality of the product and at the same time the product is considered to be biologically active [10].

\section{Effect of centrifuge speed on Refractive index of gel}

The statistical analysis of variance is given in Table 5 showed that the effect of centrifuge speed and its interaction with varying temperature, addition acetone and different holding duration on, refractive index of gel was found to be significant.

The results of effect of centrifuge speed; with different levels of acetone, temperature and duration on refractive index of gel presented in Table 6. The minimum refractive index was recorded 1.33427 at $10000 \mathrm{rpm}$ centrifuge speed keeping at $5^{\circ} \mathrm{C}$ temperature, and holding it 30 min duration for $10 \%$ addition of acetone treatment and maximum refractive index was found 1.33760 at $10^{\circ} \mathrm{C}$ centrifuge temperature and
$2000 \mathrm{rpm}$ centrifuge speed and 20 min duration for $10 \%$ addition of acetone treatment. It was observed that increase in centrifuge speed, and duration decreased the refractive index of gel, and addition of acetone also results in increase in refractive index of gel. There was no uniform trend in refractive index for varying centrifuge temperatures (Table 6).

Increase in centrifuge speed with different temperature, and varying holding time resulted decrease in the refractive index (Table 6), which is a favourable aspect in gel extraction process. By visual observation it was perceived that when centrifuge speed was increased from 2000 $\mathrm{rpm}(1.33783-1.33607)$ to $5000 \mathrm{rpm}(1.336530-1.33550)$, there was reduction found in refractive index of gel, while Increasing centrifuge speed from $5000 \mathrm{rpm}(1.33653$ - 0.33550) to $10000 \mathrm{rpm}(1.33427-$ $1.33587)$ lowered the refractive index of gel in various treatments. This may be due to more separation of fibers from pulp at higher centrifuge speed.

Obviously, further studies on the effect of acetone pretreatment with different centrifuge speed on the structural changes of aloe vera gel viscosity are essential to elucidate the exact mechanisms leading to the increase in viscosity. 
Citation: Chandegara VK, Varshney AK (2014) Effect of Centrifuge Speed on Gel Extraction from Aloe Vera Leaves. J Food Process Technol 5: 295. doi:10.4172/2157-7110.1000295

Page 6 of 6

\begin{tabular}{|c|c|c|c|c|c|c|}
\hline \multirow{4}{*}{ Experimental conditions } & \multicolumn{6}{|c|}{ Centrifuge duration (min) } \\
\hline & 10 & 20 & 30 & 10 & 20 & 30 \\
\hline & \multicolumn{3}{|c|}{ Without acetone } & \multicolumn{3}{|c|}{ With acetone (10\%) } \\
\hline & \multicolumn{6}{|c|}{ Crude gel recovery (\%) } \\
\hline Centrifuge speed $2000 \mathrm{rpm}$ and $5^{\circ} \mathrm{C}$ temperature & 42.50 & 46.50 & 51.89 & 48.17 & 49.11 & 56.50 \\
\hline Centrifuge speed $2000 \mathrm{rpm}$ and $10^{\circ} \mathrm{C}$ temperature & 44.33 & 47.06 & 48.72 & 47.22 & 50.00 & 54.50 \\
\hline Centrifuge speed $2000 \mathrm{rpm}$ and $32^{\circ} \mathrm{C}$ temperature & 45.22 & 50.11 & 51.67 & 47.61 & 49.61 & 52.56 \\
\hline Centrifuge speed $5000 \mathrm{rpm}$ and $5^{\circ} \mathrm{C}$ temperature & 45.72 & 57.33 & 61.28 & 55.67 & 59.44 & 64.61 \\
\hline Centrifuge speed $5000 \mathrm{rpm}$ and $10^{\circ} \mathrm{C}$ temperature & 51.11 & 61.56 & 64.78 & 55.61 & 57.28 & 63.83 \\
\hline Centrifuge speed $5000 \mathrm{rpm}$ and $32^{\circ} \mathrm{C}$ temperature & 54.50 & 62.94 & 62.67 & 55.72 & 60.39 & 62.50 \\
\hline Centrifuge speed $10000 \mathrm{rpm}$ and $5^{\circ} \mathrm{C}$ temperature & 63.89 & 66.33 & 70.28 & 63.44 & 70.17 & 69.56 \\
\hline Centrifuge speed $10000 \mathrm{rpm}$ and $10^{\circ} \mathrm{C}$ temperature & 63.94 & 65.22 & 67.89 & 64.00 & 67.44 & 70.22 \\
\hline Centrifuge speed $10000 \mathrm{rpm}$ and $32^{\circ} \mathrm{C}$ temperature & 64.22 & 66.28 & 69.61 & 65.44 & 67.67 & 71.33 \\
\hline
\end{tabular}

Table 6: Effect of centrifuge speed with different proportion of acetone, varying temperature and duration on gel recovery (\%) from pulp.

\section{Conclusions}

From the above results it was suggested that higher centrifuge speed found suitable for higher gel recovery and all quality parameters of gel extraction. Hence the gel extraction by centrifuge may be carried out at $10,000 \mathrm{rpm}$ speed. This experiment shows that higher centrifuge speed break the chain of sugar molecules surrounded by gel molecules and leads more gel recovery and fibreless gel. It was recommended that the extraction of gel from aloe vera by the method of centrifuge should be carried out at the rate of $10,000 \mathrm{rpm}$ centrifuge speed at $5^{\circ} \mathrm{C}$ centrifuge temperatures, for $30 \mathrm{~min}$ centrifuge duration so as to get higher gel recovery and good quality of gel.

\section{References}

1. Singh DBR, Singh ARP, Kingly, Sharma RR (2011) Effect of Aloe vera coatings on fruit quality and storability strawberry (Fragaria $x$ annassa). Indian J Agr Sci 81:407-12.

2. Hamman JH (2008) Composition and applications of Aloe vera leaf gel. Molecules 13: 1599-1616.

3. Waller GR, Mangiafico S, Ritchey CR (1978) A Chemical investigation of Aloe barbadensis Miller. Proceedings of the Oklahoma Academy of science 58: 6976.
4. Shafi N, KHAN L, khan GA (2000) Commercial extraction of gel from aloe vera (L) leaves. J Chem Soc 22: 47-49.

5. Ramachandra CT, Rao SP (2008) Processing of aloe Vera Leaf Gel: A Review. American Journal of Agricultural and Biological Sciences 3: 502-510.

6. Reynolds T, Dweck AC (1999) Aloe vera leaf gel: a review update. Journal of Ethno pharmacology 6: 3-37.

7. Yaron A (1993) Characterization of aloe vera gel composition and auto degradation and stabilization of the natural fresh gel. Phytotherapy Research 7: S11-S13.

8. Chandegara VK (2005) Development of Gel Extraction Process for aloe vera leaves. Unpublished M. Tech thesis, Junagadh Agricultural University, Junagadh.

9. Wang YT, Strong KJ (1993) Monitoring physical and chemical properties of freshly harvested field-grown aloe vera leaves. A preliminary report. Phytother Res 7: S1-S4.

10. Gowda DC, Neelisiddaiah B, Anjaneyalu YV (1979) Structural Studies of polysaccharides from aloe vera. Carbohydrates Res 72: 201-205.

11. Ni Y, Turner D, Yates KM, Tizard I (2004) Isolation and characterisation of structural components of Aloe vera L. leaf pulp. Int Immunopharmacol 4: 17451755. 